\title{
Within-subject variability of measures of beta cell function derived from a 2 h OGTT: implications for research studies
}

\author{
K. M. Utzschneider • R. L. Prigeon • J. Tong • \\ F. Gerchman • D. B. Carr • S. Zraika • J. Udayasankar • \\ B. Montgomery $\cdot$ A. Mari $\cdot$ S. E. Kahn
}

Received: 14 March 2007 / Accepted: 6 August 2007 / Published online: 11 October 2007

(C) Springer-Verlag 2007

\begin{abstract}
Aims/hypothesis Knowledge of the within-subject variability of a parameter is required to properly design and calculate sample sizes for longitudinal studies. We sought to determine the day-to-day variability of measures of beta cell function derived from an OGTT.

Methods Thirty-seven adults (13 with normal glucose tolerance, ten with impaired glucose tolerance, 14 with
\end{abstract}

K. M. Utzschneider $(\bowtie) \cdot$ J. Tong $\cdot$ F. Gerchman $\cdot$ S. Zraika $\cdot$

J. Udayasankar · B. Montgomery $\cdot$ S. E. Kahn

Department of Medicine, Division of Metabolism, Endocrinology

and Nutrition, VA Puget Sound Health Care System (151),

1660 S. Columbian Way,

Seattle, WA 98108, USA

e-mail: kutzschn@u.washington.edu

K. M. Utzschneider $\cdot$ J. Tong $\cdot$ F. Gerchman $\cdot$ S. Zraika $\cdot$

J. Udayasankar $\cdot$ B. Montgomery $\cdot$ S. E. Kahn

Department of Medicine, Division of Metabolism,

Endocrinology and Nutrition, University of Washington,

Seattle, WA, USA

\section{R. L. Prigeon}

Geriatric Research Education and Clinical Center (GRECC),

Baltimore Veterans Affairs Medical Center,

Baltimore, MD, USA

\section{R. L. Prigeon}

Division of Gerontology,

University of Maryland School of Medicine,

Baltimore, MD, USA

\section{B. Carr}

Department of Obstetrics and Gynecology,

Division of Maternal-Fetal Medicine, University of Washington, Seattle, WA, USA

\section{A. Mari}

Institute of Biomedical Engineering, National Research Council, Padua, Italy type 2 diabetes) underwent a standard $2 \mathrm{~h} 75 \mathrm{~g}$ OGTT on two separate days (median time between tests, 7 days; range, 5-14). From these data, the reproducibility of several indices of beta cell function were determined: insulinogenic index $\left(\Delta \mathrm{I}_{0-30} / \Delta \mathrm{G}_{0-30}\right)$, early C-peptide response $\left(\Delta \mathrm{CP}_{0-30} /\right.$ $\left.\Delta \mathrm{G}_{0-30}\right)$, incremental AUC insulin to glucose response (incAUC ${ }_{\text {ins }} /$ incAUC $_{\text {glu }}$ ), integrated insulin secretion response from 0 to $120 \mathrm{~min}\left(\mathrm{IS} / \mathrm{Glu}_{0-120}\right)$ and indices of beta cell function derived from a mathematical model.

Results Within-subject variability for $\Delta \mathrm{I}_{0-30} / \Delta \mathrm{G}_{0-30}(\mathrm{CV}$ $57.1 \%)$ was higher than $\Delta \mathrm{CP}_{0-30} / \Delta \mathrm{G}_{0-30}$ (CV 34.7\%). Measures integrated over the full $120 \mathrm{~min}$ of the OGTT, incAUC ins $_{\text {incAUC }} /$ glu $\left(\mathrm{CV}\right.$ 24.9\%) and IS/ $/ \mathrm{Glu}_{0-120}(\mathrm{CV}$ $17.4 \%$ ), demonstrated less variability. The mathematical model-derived measures of beta cell glucose sensitivity (CV 20.3\%) and potentiation (CV 33.0\%) showed moderate variability. The impact of the different measures' variability on sample size ( $30 \%$ change from baseline) is demonstrated by calculated sample sizes of 89 for $\Delta \mathrm{I}_{0-30} / \Delta \mathrm{G}_{0-30}, 37$ for $\Delta \mathrm{CP}_{0-30} / \Delta \mathrm{G}_{0-30}, 21$ for incAUC $\mathrm{Cins}_{\text {inc }} / \mathrm{AUC}_{\mathrm{glu}}$ and 11 for $\mathrm{IS} / \mathrm{Glu}_{0-120}$.

Conclusions/interpretation Some OGTT-derived indices of beta cell function, in particular the insulinogenic index, demonstrate high within-subject variability. Integrated measures that utilise multiple time points and measures that use C-peptide show less variability and may lead to a reduced sample size requirement.

Keywords Beta cell function - Insulin secretion . Insulin sensitivity $\cdot$ Insulinogenic index $\cdot$ Reproducibility

Abbreviations
$\begin{array}{ll}\text { ESD } & \text { extreme Studentised deviate } \\ \text { HOMA-IR } & \begin{array}{l}\text { homeostasis model assessment of insulin } \\ \text { resistance }\end{array}\end{array}$




$\begin{array}{ll}\text { IC } & \text { insulin clearance } \\ \text { ICC } & \text { intra-class correlation coefficient } \\ \text { IFG } & \text { impaired fasting glucose } \\ \text { IGT } & \text { impaired glucose tolerance } \\ \text { IQR } & \text { interquartile range } \\ \text { IS-0 } & \text { basal insulin secretion } \\ \text { ISI }_{M} & \text { Matsuda's insulin sensitivity index } \\ \text { ISI }_{S} & \text { Stumvoll's insulin sensitivity index } \\ \text { NGT } & \text { normal glucose tolerance } \\ \text { OGIS-120 } & \text { oral glucose insulin sensitivity }\end{array}$

\section{Introduction}

The OGTT is used to classify subjects as having normal glucose tolerance (NGT), impaired glucose tolerance (IGT) or diabetes. In addition to the determination of glucose tolerance, measurements made during the OGTT are frequently used to derive measures of beta cell function. This pertains in particular to epidemiology or intervention studies, where use of the OGTT is more practical than timeconsuming measures such as the IVGTT or the hyperglycaemic clamp.

Many different indices of beta cell function have been suggested. For example, the early insulin response to changes in glucose during the OGTT, termed the insulinogenic index, is often used as a measure of beta cell function. Integrated measures of the insulin response relative to the change in glucose over the time course of the OGTT have also been used. In addition, a new mathematical model has been applied to the OGTT to provide three indices of beta cell function: beta cell sensitivity to glucose, beta cell sensitivity to the rate of change of glucose and potentiation to factors such as incretin hormones and hyperglycaemia [1].

While the within-subject variability of fasting and $2 \mathrm{~h}$ measurements of glucose and insulin has been extensively documented [1-4], the reproducibility of measures of beta cell function from an OGTT has not been well characterised. Determining the within-subject variability of these measures is crucial in the design of longitudinal and intervention studies that aim to investigate changes in beta cell function and insulin sensitivity in the pathogenesis of type 2 diabetes or the prevention or treatment thereof. Longitudinal studies that rely on paired analysis and use measures of beta cell function with high within-subject variability will require much larger sample sizes. Thus, the primary aim of this study was to determine the within-subject variability of a number of different measures of beta cell function calculated using $2 \mathrm{~h}$ OGTT measurements in subjects with NGT, IGT and type 2 diabetes. In addition, we compared the variability of different measures of insulin sensitivity derived from either fasting or OGTT measures. This information provides a valuable resource for investigators, allowing them to more accurately calculate sample sizes.

\section{Methods}

Participants A total of 39 volunteers were enrolled in the study and completed two study days. Participants were categorised by glucose tolerance status, based on their fasting and $2 \mathrm{~h}$ glucose values from their first OGTT, according to the American Diabetes Association guidelines (NGT, $2 \mathrm{~h}$ glucose $<7.8 \mathrm{mmol} / \mathrm{l}$; IGT, $2 \mathrm{~h}$ glucose 7.8 $11.1 \mathrm{mmol} / \mathrm{l}$; diabetes, fasting plasma glucose $>7.0 \mathrm{mmol} / \mathrm{l}$, $2 \mathrm{~h}$ glucose $>11.1 \mathrm{mmol} / \mathrm{l}$ or use of diabetes medication). Six of the subjects with IGT also had impaired fasting glucose (IFG; fasting plasma glucose, 5.6-7.0 mmol/l). Because we were primarily interested in the variability of measures derived from values obtained during the OGTT rather than from fasting values, subjects with IFG but a normal $2 \mathrm{~h}$ glucose $(n=3)$ were included in the NGT group. CVs were also calculated for the NGT group excluding these three subjects with IFG. Four subjects with known diabetes were being treated with a stable dose of metformin that was continued on both study days. These subjects were classified as having diabetes. The additional ten subjects with diabetes were on diet treatment alone. Two subjects were excluded for the following reasons: one subject lost $4 \mathrm{~kg}$ between study days 1 and 2 (IGT on the first OGTT, NGT on the second OGTT), and one subject had a high fasting insulin level on one study day, which suggested that the study subject was not fasting (NGT subject). Thus, data from 37 subjects were used for this analysis. Subjects were otherwise in good health and were not taking medications such as steroids or niacin that would affect beta cell function or insulin sensitivity. All subjects gave written informed consent to participate in the study, which was reviewed and approved by the Human Subjects Review Committee at the University of Washington.

Study design Each subject was studied twice within 2 weeks. Subjects were instructed to fast for at least $10 \mathrm{~h}$ overnight and to refrain from exercise on the morning of the study. They were told to maintain their usual daily routine between study days. After placement of an i.v. catheter, subjects were allowed to rest for at least $15 \mathrm{~min}$ before the basal samples were drawn. A standard $75 \mathrm{~g}$ OGTT was performed and samples were drawn at $-10,-5$, $-1,15,30,60,90$ and 120 min and placed immediately on ice. Blood samples were separated and the plasma stored at $-80^{\circ} \mathrm{C}$ prior to being assayed.

Assays Samples for study days 1 and 2 were run in the same assay to avoid inter-assay variability. Plasma glucose 
concentrations were measured using the glucose oxidase method. Plasma immunoreactive insulin levels were measured using a modification of a double-antibody RIA [5]. Plasma C-peptide levels were measured by a two-site immunoenzymometric assay (Tosoh AIA 600II autoanalyzer; Tosoh Bioscience, South San Francisco, CA, USA). The intra-assay CVs were $1.4 \%$ for glucose, $8 \%$ for insulin and $3.2 \%$ for C-peptide.

Computation and statistical analysis Fasting values for glucose, insulin and C-peptide were calculated as the average of the three basal values. The insulinogenic index was calculated as the change in insulin divided by the change in glucose over the first $30 \mathrm{~min}$ of the OGTT $\left(\Delta \mathrm{I}_{0-30}\right)$ $\left.\Delta \mathrm{G}_{0-30}\right)$. As a comparator to the insulinogenic index, the change in C-peptide divided by the change in glucose over the first $30 \mathrm{~min}$ of the OGTT $\left(\Delta \mathrm{CP}_{0-30} / \Delta \mathrm{G}_{0-30}\right)$ was also computed. The incremental AUCs for insulin (incAUC $\mathrm{ins}_{\text {) }}$ ) and $\mathrm{C}$-peptide (incAUC $\mathrm{CP}_{\mathrm{CP}}$ ) were computed by applying the trapezoidal rule on values from 0 to $120 \mathrm{~min}$ after subtracting the basal (fasting) value, and the corresponding value for glucose (incAUC $\mathrm{glu}_{\text {lu }}$ ) was computed in a similar manner. The ratios of these parameters (incAUC ${ }_{\text {ins }} /$ incAUC $_{\text {glu }}$ and incAUC $\mathrm{CP}_{\mathrm{incAUC}} \mathrm{iUlu}_{\mathrm{glu}}$ ) were evaluated as measures of insulin release during the entire OGTT. Basal insulin secretion (IS-0), and the total integrated insulin secretion divided by the mean change in glucose from 0 to $120 \mathrm{~min}\left(\mathrm{IS} / \mathrm{Glu}_{0-120}\right)$ were determined using C-peptide deconvolution as previously described [6]. Based on these measures of insulin secretion, estimates of basal insulin clearance (IC) were calculated as IS- 0 divided by average fasting insulin, and estimates of total insulin clearance $\left(\mathrm{IC}_{0-120}\right)$ were calculated as integrated insulin secretion from 0 to 120 min divided by the average insulin concentration from 0 to $120 \mathrm{~min}$.

Parameters of beta cell function were derived from mathematical analysis of plasma glucose and C-peptide concentrations during the OGTT, according to a previously developed model [7]. Beta cell glucose sensitivity denotes the mean slope of the relationship relating insulin secretion to the glucose concentration, and reflects the response of the beta cell to prevailing plasma glucose concentrations in the steady state. Rate sensitivity denotes the dynamic insulin secretion component that is a function of the rate of change of the plasma glucose concentration during the OGTT. The dose response is modulated by a timedependent potentiation factor that is normalised such that the $0-120 \mathrm{~min}$ integrated value is 1.0 for each experiment. The ratio of the potentiation factor at the end of the OGTT (100-120 $\mathrm{min}$ ) to the potentiation factor at the beginning of the OGTT $(0-20 \mathrm{~min})$ is defined as the potentiation parameter. Although the precise physiological implications of the potentiation parameter are unknown, it may reflect the effects of incretin hormones such as glucose-dependent insulinotropic peptide and glucagon-like peptide-1.

Several indices of insulin sensitivity or insulin resistance were determined, including: (1) fasting insulin; (2) homeostasis model assessment of insulin resistance (HOMA-IR), using non-specific insulin (using the calculator available from http://www.dtu.ox.ac.uk, last accessed in August 2007) [8]; (3) the model-derived oral glucose insulin sensitivity (OGIS120 ), which is calculated using glucose and insulin concentrations at baseline and 90 and 120 min [9]; (4) Matsuda's insulin sensitivity index $\left(\mathrm{ISI}_{\mathrm{M}}\right)$, which is calculated as 10,000 /(fasting glucose $\times$ fasting insulin $\times$ average glucose OGTT $\times$ average insulin OGTT) ${ }^{1 / 2}$ [10]; and Stumvoll's insulin sensitivity index $\left(\mathrm{ISI}_{\mathrm{S}}\right.$ ), which is calculated as 0.226 $-0.0032 \times$ BMI $-0.0000645 \times$ Ins $120-0.00375 \times$ Gluc90 [11]. All indexes were calculated using SI units.

The data were ln-transformed to correct for heteroscedasticity with variance increasing with increasing mean, except for two variables, $2 \mathrm{~h}$ glucose and rate sensitivity, which were already homoscedastic. For these two variables an estimated $\mathrm{CV}$ based on the mean for the group was calculated as the SD divided by the mean. Because the mean $2 \mathrm{~h}$ glucose differed between glucose tolerance categories, estimates for the $\mathrm{CV}$ for $2 \mathrm{~h}$ glucose are reported for each category only. Since $\ln$-transformation cannot be performed on negative values, the following numbers of subjects were excluded from analysis: $\operatorname{ISI}_{\mathrm{S}}(n=$ 7, four IGT and three diabetes), $\Delta \mathrm{I}_{0-30} / \Delta \mathrm{G}_{0-30}(n=1)$, $\Delta \mathrm{CP}_{0-30} / \Delta \mathrm{G}_{0-30}(n=2)$, incAUC ${ }_{\text {ins }} /$ incAUC $_{\text {glu }}(n=1)$ and incAUC $_{\mathrm{CP}} /$ incAUC $_{\mathrm{glu}}(n=1)$.

The distribution of the difference between study days 1 and 2 (using ln-transformed variables as indicated above) was examined visually, and outliers were tested using the extreme Studentised deviate (ESD) statistic (|extrememean|/SD). Values outside the 95th percentile from the mean (ESD, >2.98) were excluded as outliers. One outlier was excluded for each of the following variables: $\ln$ [fasting C-peptide], $\ln \left[\mathrm{ISI}_{\mathrm{S}}\right], \ln [\mathrm{OGIS}-120], \ln \left[\Delta \mathrm{I}_{0-30} / \Delta \mathrm{G}_{0-30}\right], \ln$ $\left[\Delta \mathrm{CP}_{0-30} / \Delta \mathrm{G}_{0-30}\right], \ln \left[\right.$ incAUC $_{\text {ins }} /$ incAUC $\left._{\text {glu }}\right], \ln [$ IS-0], $\ln$ [IS/Glu $\left.{ }_{0-120}\right], \ln [$ glucose sensitivity], rate sensitivity and $\ln [$ basal IC].

Bland-Altman plots were used to assess for systematic bias in variables between the first and second study day. The $95 \%$ CI for the mean difference between study days was calculated. If the $95 \% \mathrm{CI}$ included zero then there was no systematic bias. Repeated-measures ANOVA with study day as the within-subject factor and glucose tolerance category as the between-subjects factor was performed on ln-transformed data. Based on ANOVA, the significance of differences between day 1 and day 2 was determined for each variable and differences by glucose tolerance category were assessed. The $\mathrm{CV}$ of the non-transformed variable was calculated from the mean square error of the ln-transformed 
Table 1 Measures from the OGTT study day 1 and study day 2 for all study subjects

\begin{tabular}{|c|c|c|c|c|c|c|c|}
\hline \multirow[b]{2}{*}{ Study day } & \multicolumn{2}{|l|}{ NGT $(n=13)$} & \multicolumn{2}{|l|}{ IGT $(n=10)$} & \multicolumn{2}{|c|}{ Diabetes $(n=14)$} & \multirow{2}{*}{$\begin{array}{l}\text { ANOVA } \\
\text { (between- } \\
\text { groups } p \text { value) }\end{array}$} \\
\hline & 1 & 2 & 1 & 2 & 1 & 2 & \\
\hline BMI $\left(\mathrm{kg} / \mathrm{m}^{2}\right)$ & $26.6 \pm 6.4$ & $26.7 \pm 6.4$ & $38.2 \pm 9.3$ & $38.1 \pm 9.4$ & $31.8 \pm 4.7$ & $31.7 \pm 4.7$ & 0.001 \\
\hline FPG (mmol/l) & $5.13(0.88)$ & $5.07(0.73)$ & $5.83(0.72)$ & $5.74(1.19)$ & $6.78(1.68)$ & $6.78(2.58)$ & 0.002 \\
\hline $2 \mathrm{~h}$ glucose $(\mathrm{mmol} / \mathrm{l})$ & $5.48(1.72)$ & $5.52(2.42)$ & $9.65(1.86)$ & $8.84(3.07)$ & $14.26(6.61)$ & $13.22(6.31)$ & 0.026 \\
\hline $\begin{array}{l}\text { Fasting insulin } \\
(\mathrm{pmol} / \mathrm{l})\end{array}$ & $51.7(26.2)$ & $48.4(22.7)$ & $82.4(15.1)$ & $75.3(28.5)$ & $79.9(71.3)$ & $91.1(46.5)$ & 0.003 \\
\hline HOMA-IR & $0.95(0.83)$ & $0.93(0.50)$ & $1.58(0.33)$ & $1.42(0.56)$ & $1.68(1.41)$ & $1.79(1.18)$ & 0.001 \\
\hline $\mathrm{ISI}_{\mathrm{M}}$ & $12.49(7.80)$ & $14.17(7.34)$ & $6.95(2.34)$ & $6.72(3.13)$ & $5.85(3.87)$ & $5.51(4.50)$ & $<0.001$ \\
\hline $\mathrm{ISI}_{\mathrm{S}}$ & $0.110(0.032)$ & $0.111(0.064)$ & $0.021(0.045)$ & $0.020(0.045)$ & $0.037(0.050)$ & $0.033(0.045)$ & 0.001 \\
\hline $\begin{array}{l}\text { OGIS-120 } \\
\left(\mathrm{ml} \mathrm{min}^{-1} \mathrm{~m}^{-2}\right)\end{array}$ & $408 \pm 49$ & $411 \pm 55$ & $300 \pm 82$ & $305 \pm 55$ & $277 \pm 60$ & $289 \pm 50$ & $<0.001$ \\
\hline Fasting CP (nmol/1) & $0.57(0.22)$ & $0.57(0.18)$ & $0.91(0.22)$ & $0.82(0.15)$ & $0.83(0.50)$ & $0.87(0.50)$ & 0.001 \\
\hline $\begin{array}{l}\text { IS-0 } \\
\left(\mathrm{pmol} \mathrm{min}{ }^{-1} \mathrm{~m}^{-2}\right)\end{array}$ & $77.8(20.3)$ & 74.7 (13.9) & $106.4(26.8)$ & $96.9(7.4)$ & $103.4(64.9)$ & $106.9(65.6)$ & 0.001 \\
\hline $\begin{array}{c}\Delta \mathrm{I}_{0-30} / \Delta \mathrm{G}_{0-30} \\
(\mathrm{pmol} / \mathrm{mmol})\end{array}$ & $112.5(49.1)$ & $123.1(95.5)$ & $101.8(73.9)$ & $99.9(94.7)$ & $57.8(48.7)$ & $64.3(79.2)$ & 0.017 \\
\hline $\begin{array}{l}\Delta \mathrm{CP}_{0-30} / \Delta \mathrm{G}_{0-30} \\
(\mathrm{nmol} / \mathrm{mmol})\end{array}$ & $0.46(0.26)$ & $0.47(0.43)$ & $0.35(0.11)$ & $0.40(0.18)$ & $0.20(0.21)$ & $0.22(0.32)$ & 0.005 \\
\hline $\begin{array}{l}\text { IncAUCins/ } \\
\text { incAUCglu } \\
(\mathrm{pmol} / \mathrm{mmol})\end{array}$ & $164.9(384.7)$ & $191.5(315.3)$ & $128.3(31.0)$ & $122.6(145.8)$ & $50.2(81.0)$ & $49.1(100.6)$ & 0.003 \\
\hline $\begin{array}{l}\mathrm{IncAUC}_{\mathrm{CP}} / \\
\text { incAUCglu } \\
(\mathrm{nmol} / \mathrm{mmol})\end{array}$ & $1.04(2.14)$ & $1.02(1.69)$ & $0.56(0.11)$ & $0.50(0.30)$ & $0.31(0.34)$ & $0.24(0.34)$ & $<0.001$ \\
\hline 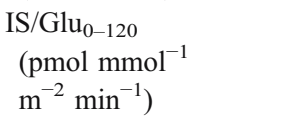 & $194.4(335.8)$ & $185.3(272.3)$ & $132.0(33.8)$ & $121.0(63.7)$ & $81.7(64.0)$ & $84.0(103.3)$ & $<0.001$ \\
\hline $\begin{array}{l}\text { Glucose sensitivity } \\
\left(\mathrm{pmol}[\mathrm{mmol} / 1]^{-1}\right. \\
\left.\mathrm{m}^{-2} \min ^{-1}\right)\end{array}$ & $126.9(45.3)$ & $124.0(45.3)$ & $80.4(51.6)$ & $86.5(44.4)$ & $49.8(55.3)$ & $54.9(63.6)$ & $<0.001$ \\
\hline $\begin{array}{l}\text { Rate sensitivity } \\
\qquad\left(\mathrm{pmol}[\mathrm{mmol} / \mathrm{l}]^{-1} \mathrm{~m}^{-2}\right)\end{array}$ & $870.7(441.1)$ & $818.5(637.1)$ & $838.1(295.0)$ & $816.2(720.1)$ & $346.2(404.6)$ & $197.2(621.0)$ & 0.075 \\
\hline Potentiation & $1.76 \pm 0.67$ & $1.61 \pm 0.79$ & $1.47 \pm 0.80$ & $1.26 \pm 0.48$ & $1.47 \pm 0.77$ & $1.07 \pm 0.37$ & 0.14 \\
\hline Basal IC $\left(1 \min ^{-1} \mathrm{~m}^{-2}\right)$ & $1.43 \pm 0.33$ & $1.51 \pm 0.33$ & $1.24 \pm 0.30$ & $1.33 \pm 0.37$ & $1.22 \pm 0.31$ & $1.27 \pm 0.23$ & 0.21 \\
\hline $\begin{array}{l}\mathrm{IC}_{0-120} \\
\left(\times 10^{3} 1 \mathrm{~min}^{-1} \mathrm{~m}^{-2}\right)\end{array}$ & $1.09 \pm 0.17$ & $1.07 \pm 0.21$ & $0.87 \pm 0.27$ & $0.90 \pm 0.25$ & $0.98 \pm 0.24$ & $0.95 \pm 0.19$ & 0.09 \\
\hline
\end{tabular}

Data are reported as means \pm SD for normally distributed data and as medians (IQR) for non-normally distributed data

The equations used to calculate the indexes (HOMA-IR, ISI $\mathrm{M}_{\mathrm{M}}, \mathrm{ISI}_{\mathrm{S}}$ ) are presented in the Methods

Basal IC, basal insulin clearance; CP, C-peptide; FPG, fasting plasma glucose; $\mathrm{IC}_{0-120}$, insulin clearance from 0-120 min incAUC CP $_{\text {incAUCglu, }}$ the incremental area under the curve C-peptide to glucose response; incAUCins/incAUCglu, the incremental AUC insulin to glucose response; IS0 , basal insulin secretion; IS/ $\mathrm{Glu}_{0-120}$, integrated insulin secretion divided by the mean change in glucose from $0-120$ min; ISI $\mathrm{M}_{\mathrm{M}}$, Matsuda's insulin sensitivity index; ISI , Stumvoll's insulin sensitivity index; OGIS-120, oral glucose insulin sensitivity

variable as: $\mathrm{CV}=[\exp (\text { Mean Square } \text { within })-1]^{1 / 2}[12]$. Differences in $\mathrm{CV}$ between glucose tolerance categories were assessed using the Kruskal-Wallis rank sum test.

The intra-class correlation coefficient (ICC; defined as the proportion of the total variance that is due to betweensubject variance) was computed for each variable using a one-way random effects model on ln-transformed data for all variables except $2 \mathrm{~h}$ glucose and rate sensitivity. The
ICC demonstrates how the reproducibility of a measure compares with the variation in the specified population.

The confidence limits of the CVs were determined from 10,000 bootstrap replications of the original data, i.e. the original data was re-sampled with replacement. With the bootstrap method, re-sampling of data with replacement is approximately equivalent to sampling from the (unknown) original population, thus confidence limits can be deter- 

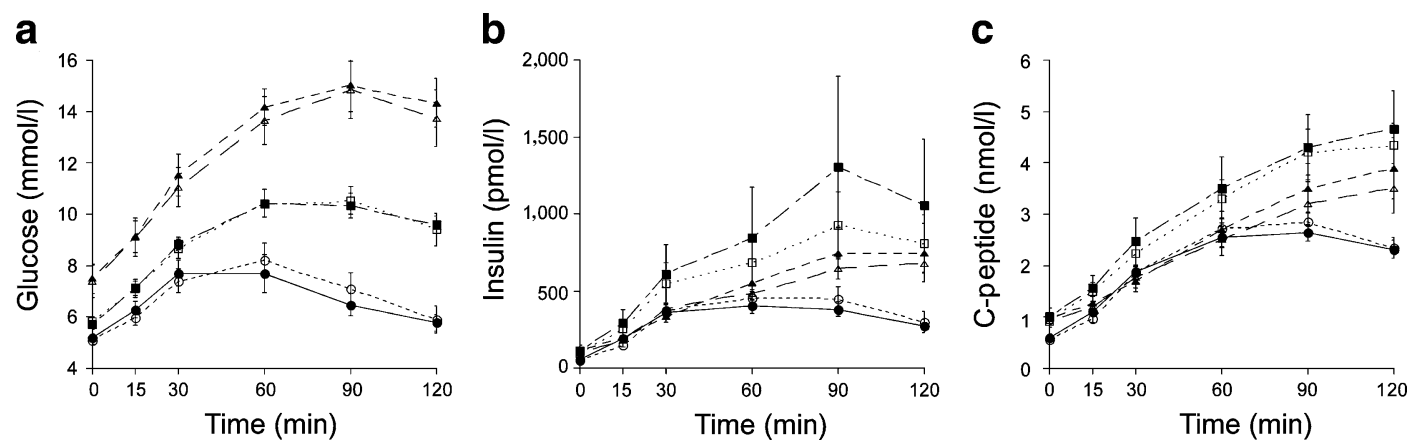

Fig. 1 Glucose (a), insulin (b) and C-peptide (c) curves for study days 1 and 2 for each glucose tolerance category. Data are presented as means \pm SEM. Circles, NGT; squares, IGT; triangles, diabetes; closed symbols represent study day 1 and open symbols represent study day 2

mined using multiple bootstrap replications. Using this approach, the $95 \%$ confidence limit values were then determined as the 2.5 and 97.5 percentile rankings of the replicate values [13].

Statistical analyses were performed using SPSS software (version 14; SPSS, Chicago, IL, USA). Data that are not normally distributed are presented as medians and interquartile range (IQR). A $p$ value of $<0.05$ was considered statistically significant.

\section{Results}

Subject characteristics Thirteen subjects were categorised as having NGT (seven men, six women), ten as having IGT (three men, seven women) and 14 as having diabetes (eight men, six women). The median time interval between study day 1 and study day 2 was 7 days (range, 5-14) and did not differ significantly between glucose tolerance categories. NGT subjects (age $44.3 \pm 3.2$ years; mean $\pm \mathrm{SD}, p<0.05$ ) were significantly younger than subjects with IGT (56.8 \pm 4.5 years) or diabetes $(60.6 \pm 2.2$ years). Subject characteristics are presented in Table 1. All variables showed significant differences between the glucose tolerance categories, with the exception of the rate sensitivity, potentiation parameters and measures of insulin clearance.

The glucose, insulin and C-peptide responses during the OGTT were similar between study day 1 and day 2 (Fig. 1). There were small but statistically significant differences between study day 1 and study day 2 when analysed for all subjects for the following variables (median [IQR]): fasting insulin (76.9 [38.7] vs 65.1 [45.4] pmol/1, $p=0.02$ ), HOMA-IR (1.49 [0.82] vs 1.29 [0.85], $p=0.02)$, glucose sensitivity (76.4 [68.8] vs $84.0[83.9]$, $\mathrm{pmol}[\mathrm{mmol} / 1]^{-1} \mathrm{~m}^{-2}$ $\left.\min ^{-1}, p=0.04\right)$, and potentiation $(1.57 \pm 0.74$ vs $1.31 \pm 0.61$, $p=0.04)$. When analysed by glucose tolerance category, BMI was significantly higher on study day 2 vs day 1 in the NGT group $(p=0.008)$, glucose sensitivity was significantly higher on study day 2 vs day 1 in the diabetes group ( $p=$ 0.008 ) and potentiation was higher on study day 1 vs day 2 in the diabetes group $(p=0.02)$. There were no statistically significant differences between study day 1 and day 2 for any of the other variables.

Bland-Altman plots Bland-Altman plots for fasting and $2 \mathrm{~h}$ measures are presented in Fig. 2, and measures of insulin response, secretion and mathematical model-derived beta cell function are presented in Fig. 3. The ln-transformed values are shown, except for $2 \mathrm{~h}$ glucose and rate sensitivity.

The $95 \%$ CI for the mean of the difference between study days did not include zero for the following variables: fasting insulin, glucose sensitivity and potentiation, although the $95 \%$ CI's lower bounds for these variables were very close to zero, suggesting a relatively unimportant effect of the day of study on measure values.

Bland-Altman plots were also constructed for $\ln$ [HOMAIR], $\ln \left[\right.$ OGIS-120], $\ln \left[\mathrm{ISI}_{\mathrm{M}}\right.$ ], $\ln \left[\mathrm{ISI}_{\mathrm{S}}\right], \ln \left[\right.$ incAUC $_{\mathrm{CP}} /$ incAUC $\left._{\text {glu }}\right]$ and $\ln [\mathrm{IC}]$, and all demonstrated homoscedasticity (plots not shown). The $95 \%$ CIs for these variables included zero for $\ln \left[\mathrm{ISI}_{\mathrm{S}}\right]$ ( -0.056 to 0.137$), \ln [$ OGIS-120] $(-0.055$ to 0.020$), \ln \left[\right.$ incAUC $_{\mathrm{CP}} /$ incAUC $\left._{\text {glu }}\right](-0.111$ to $0.057), \ln \left[\right.$ basal IC] $(-0.091$ to 0.003$)$ and $\ln \left[\mathrm{IC}_{0-120}\right]$ ( -0.048 to 0.054$)$, but did not include zero for $\ln$ [HOMAIR] $(0.016$ to 0.169$)$ or $\ln \left[\mathrm{ISI}_{\mathrm{M}}\right](-0.060$ to -0.134$)$.

Within-subject variability Within-subject variability was computed, and the CVs for each variable are presented in Table 2. The insulinogenic index $\left(\Delta \mathrm{I}_{0-30} / \Delta \mathrm{G}_{0-30}\right)$ showed marked within-subject variability. There was less variability when C-peptide rather than insulin was used. The values for incAUC $_{\text {ins }} /$ incAUC $_{\text {glu }}$, incAUC $C_{\mathrm{CP}} /$ incAUC $_{\text {glu }}$ and the integrated insulin secretion measure using $\mathrm{C}$-peptide deconvolution (IS/Glu $\mathrm{Gl}_{0-120}$ ), exhibited much less variability than either of the early $30 \mathrm{~min}$ responses. Glucose sensitivity showed moderate variability, whereas that for the potentiation factor was higher. Measures of insulin sensitivity, including fasting insulin, HOMA-IR, ISI $_{\mathrm{M}}$, ISI $\mathrm{S}_{\mathrm{S}}$ and OGIS120 , had CVs that ranged from 7.3 to $24.0 \%$.

The CVs did not differ by glucose tolerance category, with the exception of fasting C-peptide $(p<0.05)$ and IS-0 
Fig. 2 Bland-Altman plots for fasting and $2 \mathrm{~h}$ glucose, fasting insulin and fasting C-peptide.

Variables that demonstrated heteroscedasticity (increasing variability with increasing mean) were ln-transformed. Circles, NGT; squares, IGT; triangles, diabetes; dashed lines indicate the $95 \%$ CIs for the mean difference between study days. a $\ln$ [fasting plasma glucose], b 2 h plasma glucose, c ln [fasting insulin], $\mathbf{d} \ln [$ fasting Cpeptide]. Fasting insulin showed a slight bias, with higher values on study day 1 vs 2

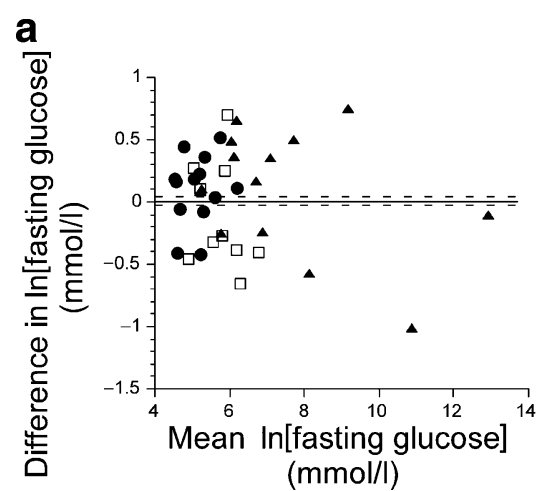

b

C

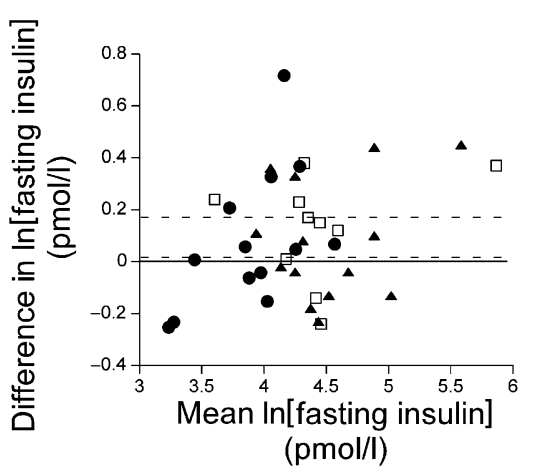

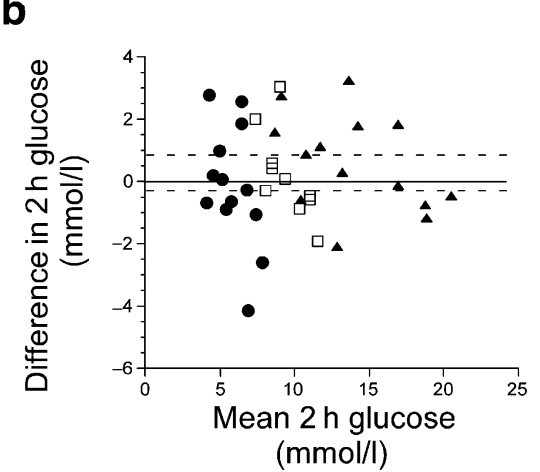

d

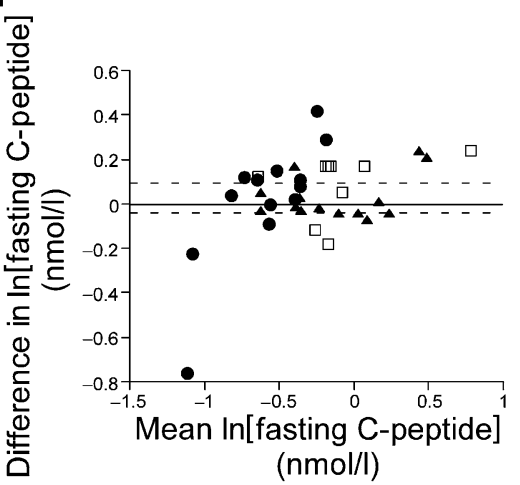

$(p<0.05$; Table 2). Exclusion of those subjects with diabetes who were on metformin did not alter the results appreciably (Table 2).

When the three subjects with IFG were removed from the NGT group, most CVs did not change appreciably (FPG $4.5 \%$, OGIS-120 8.3\%, ISI ${ }_{\mathrm{M}} 10.9 \%$, ISI $_{\mathrm{S}} 19.5 \%$, OGIS-120 $8.3 \%$, IS-0 $8.4 \%, \Delta \mathrm{I}_{0-30} / \Delta \mathrm{G}_{0-30} 43.0 \%$, incAUC $\mathrm{ins}^{\prime}$ inc $A U C_{\text {glu }} 29.6 \%$, inc AUC CP $_{\text {inc }}$ AUC $_{\text {glu }} 21.6 \%$, glucose sensitivity $18.0 \%$, potentiation $47.2 \%$, basal IC $11.5 \%$, $\left.\mathrm{IC}_{0-120} 11.2 \%\right)$. However, the CVs for fasting insulin $(13.1 \%)$, HOMA-IR (12.7\%), fasting C-peptide (8.4\%) and $\Delta \mathrm{CP}_{0-30} /$ $\Delta \mathrm{G}_{0-30}(21.9 \%)$ decreased somewhat when the subjects with IFG were removed.

The intra-class correlation coefficient The ICC was determined for each variable for all subjects and the data are presented in Fig. 4. Most variables showed excellent ICCs $(>0.75)$ in this population sample. Both the early insulin and C-peptide responses showed relatively lower ICCs, while rate sensitivity and potentiation demonstrated much poorer ICCs. The ICC for $\ln \left[\right.$ incAUC $_{\mathrm{CP}} /$ incAUC $\left._{\mathrm{glu}}\right]$ (0.97; 95\% CI $0.95-0.99)$ was very similar to that for IS/ $\mathrm{Glu}_{0-120}$ and is not included in the figure.

Sample size calculations Samples size estimates were calculated based on the within-subject SDs for all subjects for paired $t$ test comparisons using an $\alpha$-level of 0.05 and a power of $90 \%$ to detect a change from baseline of 20,30 and $50 \%$.
Estimates used ln-transformed data for all subjects and are listed in Table 3. The early insulin and C-peptide responses would require much larger sample sizes than other measures.

\section{Discussion}

We have shown that there are important differences in within-subject variability for beta cell measures obtained from an OGTT. Thus, while easy to perform, the OGTT is hampered by high variability, particularly in measures of the early insulin response. Variability was decreased by using C-peptide rather than insulin and by using integrated measures. Use of a mathematical model to assess beta cell function showed that while the beta cell glucose sensitivity measure had modest variability, the potentiation parameter and rate sensitivity had higher variability.

We demonstrated a CV of $57.1 \%$ for the insulinogenic index. For comparison, the $\mathrm{CV}$ of the acute insulin response to intravenous glucose determined by this research group is less than half that (CV 20.6\%) [14], which demonstrates the superior reproducibility of the intravenous test. Although within-subject variability may be affected by differences in protocol, technique or assay precision, our within-subject variability for the insulinogenic index in NGT subjects (CV 41.1\%) is similar to that reported by Schousboe et al. (CV 34\%) [15]. Thus, we believe the high variability of the insulinogenic index is correct. We eliminated inter-assay 
Fig. 3 Bland-Altman plots for measures of insulin secretion and beta cell function are presented. Variables demonstrating heteroscedasticity were $\ln$ transformed. Circles, NGT; squares, IGT; triangles, diabetes; dashed lines indicate the $95 \%$ CIs for the mean difference between study days.. a $\ln \left[\Delta \mathrm{I}_{0-30} /\right.$ $\left.\Delta \mathrm{G}_{0-30}\right], \mathbf{b} \ln \left[\Delta \mathrm{CP}_{0-30} / \Delta \mathrm{G}_{0-30}\right]$, c $\ln \left[\right.$ incAUC $_{\text {ins }} /$ incAUC $\left._{\text {glu }}\right], \mathbf{d} \ln$ [IS/Glu $\left.{ }_{0-120}\right]$, e $\ln [\mathrm{IS}-0]$, f $\ln$ [glucose sensitivity], g rate sensitivity, $\mathbf{h} \ln [$ potentiation]. Glucose sensitivity and potentiation showed a slight bias as the $95 \%$ CI did not include 0 a

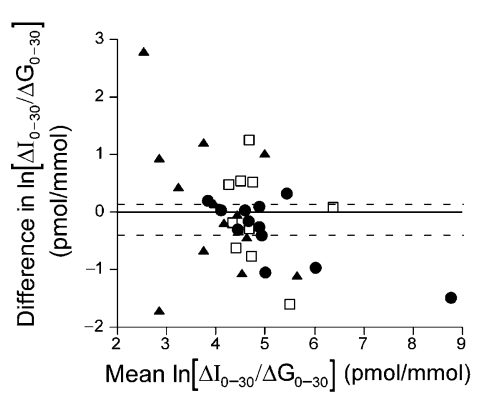

C 긍

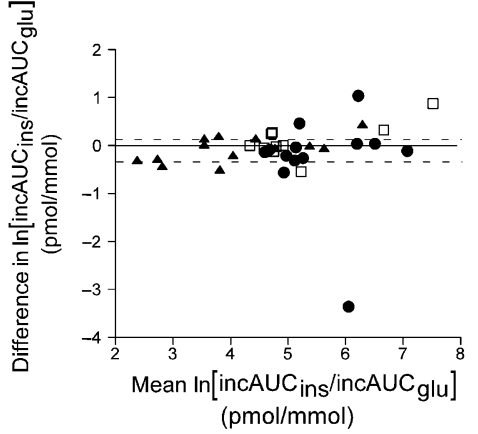

e

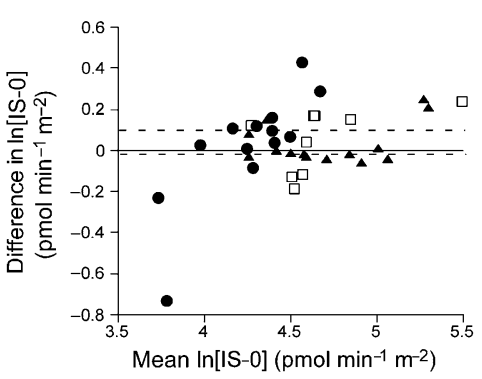

g

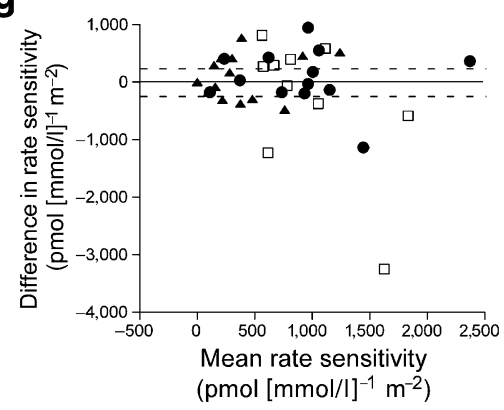

b

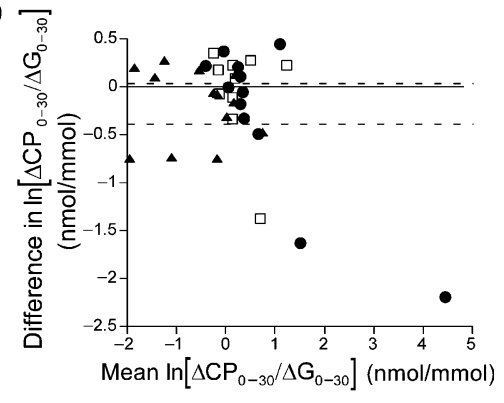

d

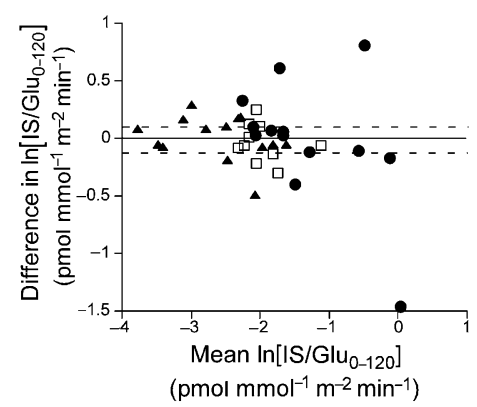

f

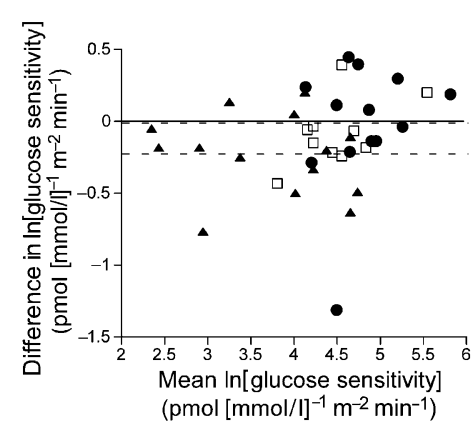

h

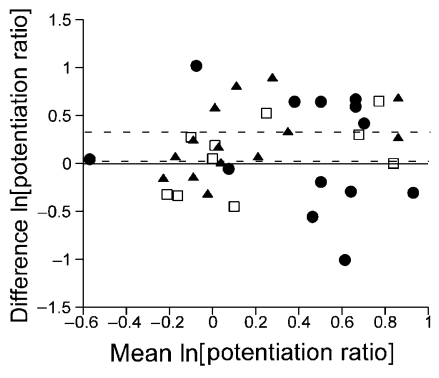

variability by making all the sample measurements for each individual in the same assay. Variability may be greater in studies in which the samples from the same subject are assayed at different times. In addition, the variability may be increased by other factors, such as prolonged storage between study visits.

The use of integrated AUC responses from 0 to $120 \mathrm{~min}$ and C-peptide measures decreased the within-subject variability compared with the insulinogenic index. In particular, the ratios of the incremental AUCs for insulin or C-peptide to the corresponding values for glucose

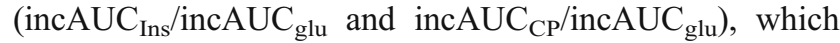
are easy to calculate and do not require models, result in very acceptable within-subject variability and may be good alternative measures of the insulin response. The early $\mathrm{C}$-peptide measure and the integrated insulin secretion measures using C-peptide also demonstrated less withinsubject variability. The higher analytical variability of the insulin assay (intra-assay CV $8 \%$ for insulin vs $3.2 \%$ for C-peptide) and variability in insulin clearance may contribute to this finding. However, the $\mathrm{C}$-peptide assay is relatively expensive, C-peptide is less stable in stored 
Table $2 \mathrm{CV}$ for OGTT measures

\begin{tabular}{|c|c|c|c|c|c|}
\hline & $\begin{array}{l}\text { NGT } \\
(n=13)\end{array}$ & $\begin{array}{l}\text { IGT } \\
(n=10)\end{array}$ & $\begin{array}{l}\text { Diabetes } \\
(n=14)\end{array}$ & $\begin{array}{l}\text { Diabetes } \\
\text { (no medication: } n=10 \text { ) }\end{array}$ & $\begin{array}{l}\text { All } \\
(n=37)\end{array}$ \\
\hline FPG & $4.0(2.2-5.1)$ & $5.2(2.9-6.5)$ & $4.3(2.8-5.2)$ & $4.8(3.0-5.8)$ & $4.5(3.7-5.1)$ \\
\hline $2 \mathrm{~h} \mathrm{Glucose} \mathrm{e}^{\mathrm{a}}$ & $24.9(14.4-32.1)$ & $11.0(4.5-14.6)$ & $8.0(5.3-9.8)$ & $5.9(3.5-7.4)$ & - \\
\hline Fasting insulin & $19.3(9.7-26.0)$ & $14.3(6.8-18.3)$ & $16.5(10.7-19.5)$ & $17.1(11.1-19.9)$ & $16.6(12.8-19.9)$ \\
\hline HOMA-IR & $19.1(9.5-25.9)$ & $14.4(7.0-18.3)$ & $16.1(10.4-19.1)$ & $17.0(11.1-19.8)$ & $16.4(12.5-19.9)$ \\
\hline $\mathrm{ISI}_{\mathrm{M}}$ & $14.0(9.2-17.6)$ & $20.4(8.1-26.8)$ & $14.4(7.0-18.1)$ & $16.8(7.6-20.5)$ & $15.8(11.3-19.4)$ \\
\hline $\mathrm{ISI}_{\mathrm{S}}$ & $18.9(3.2-27.0)$ & $24.0^{\mathrm{b}}(1.7-30.9)$ & $13.5^{\mathrm{c}}(7.4-17.1)$ & $13.2^{\mathrm{d}}(6.1-17.5)$ & $18.1(10.2-24.5)$ \\
\hline OGIS-120 & $7.3(4.3-8.9)$ & $7.3^{\mathrm{d}}(2.6-10.0)$ & $8.5(4.8-10.9)$ & $9.7(4.2-12.5)$ & $7.8(5.8-9.5)$ \\
\hline Fasting C-peptide & $11.5^{\mathrm{e}}(5.3-15.5)$ & $10.8(4.7-12.8)$ & $7.2(2.6-9.0)$ & $8.3(3.2-9.8)$ & $9.7(7.4-11.8)$ \\
\hline IS-0 & $11.8^{\mathrm{e}}(5.2-16.0)$ & $10.8(4.9-12.9)$ & $7.2(3.0-9.0)$ & $8.1(3.9-9.6)$ & $9.8(7.3-12.0)$ \\
\hline$\Delta \mathrm{I}_{0-30} / \Delta \mathrm{G}_{0-30}$ & $41.1^{\mathrm{e}}(18.3-53.2)$ & $62.9(30.9-88.2)$ & $69.1^{\mathrm{f}}(41.5-90.2)$ & $79.7(42.8-105.0)$ & $57.1(42.3-69.9)$ \\
\hline$\Delta \mathrm{CP}_{0-30} / \Delta \mathrm{G}_{0-30}$ & $42.3^{\mathrm{c}}(14.6-64.7)$ & $37.4(9.6-57.4)$ & $27.3(17.6-32.2)$ & $32.3(21.0-36.1)$ & $34.7(21.1-45.8)$ \\
\hline IncAUC $_{\text {ins }} /$ incAUC $_{\text {glu }}$ & $29.4^{\mathrm{e}}(9.2-42.4)$ & $27.0(10.5-37.8)$ & $19.2(11.9-24.4)$ & $22.7(13.1-28.4)$ & $24.9(16.2-32.1)$ \\
\hline IncAUC $_{C P} /$ incAUC $_{\text {glu }}$ & $25.5(12.9-34.5)$ & $14.2(7.0-18.5)$ & $10.0^{f}(7.2-11.7)$ & $9.0^{\mathrm{d}}(4.4-10.5)$ & $17.7(11.3-22.9)$ \\
\hline $\mathrm{IS} / \mathrm{Glu}_{0-120}$ & $24.0^{\mathrm{e}}(10.2-31.8)$ & $11.7(6.4-15.0)$ & $13.8(7.2-19.2)$ & $15.2(5.8-21.7)$ & $17.4(11.1-22.8)$ \\
\hline Glucose sensitivity & $17.2^{\mathrm{e}}(11.4-20.7)$ & $16.5(6.2-22.1)$ & $20.3(12.6-25.4)$ & $23.3(12.2-29.0)$ & $20.3(15.3-24.5)$ \\
\hline Rate sensitivity $^{\mathrm{a}}$ & $42.1(20.5-58.2)$ & $40.5^{\mathrm{d}}(19.3-50.7)$ & $114.8(74.4-136.1)$ & $76.2(35.0-89.6)$ & $44.6(33.0-54.9)$ \\
\hline Potentiation & $43.6(27.8-55.5)$ & $26.7(15.8-33.0)$ & $26.9(17.1-33.0)$ & $26.1(12.9-33.2)$ & $33.0(25.5-39.8)$ \\
\hline Basal IC & $11.7^{\mathrm{e}}(7.1-14.7)$ & $6.0(3.8-7.4)$ & $10.8(7.4-13.2)$ & $10.1(5.9-12.3)$ & $9.9(7.6-11.6)$ \\
\hline $\mathrm{IC}_{0-120}$ & $11.7(7.7-14.4)$ & $11.2(6.2-14.4)$ & $9.6(4.3-13.6)$ & $11.4(4.8-15.9)$ & $10.8(8.2-13.0)$ \\
\hline
\end{tabular}

Data are presented as $\mathrm{CV}$ in percentages $(95 \% \mathrm{CI})$

${ }^{\text {a }}$ Estimates based on $\mathrm{SD} /$ mean

${ }^{\mathrm{b}} n=5 ;{ }^{\mathrm{c}} n=11 ;{ }^{\mathrm{d}} n=9 ;{ }^{\mathrm{e}} n=12 ;{ }^{\mathrm{f}} n=13$

samples and C-peptide deconvolution techniques may not be readily available to all investigators. These factors must be balanced against the decreased sample size requirement when C-peptide is used.

While the beta cell glucose sensitivity measure derived from a mathematical model showed within-subject variability similar to that of the integrated insulin responses, estimates of the rate sensitivity and potentiation ratio

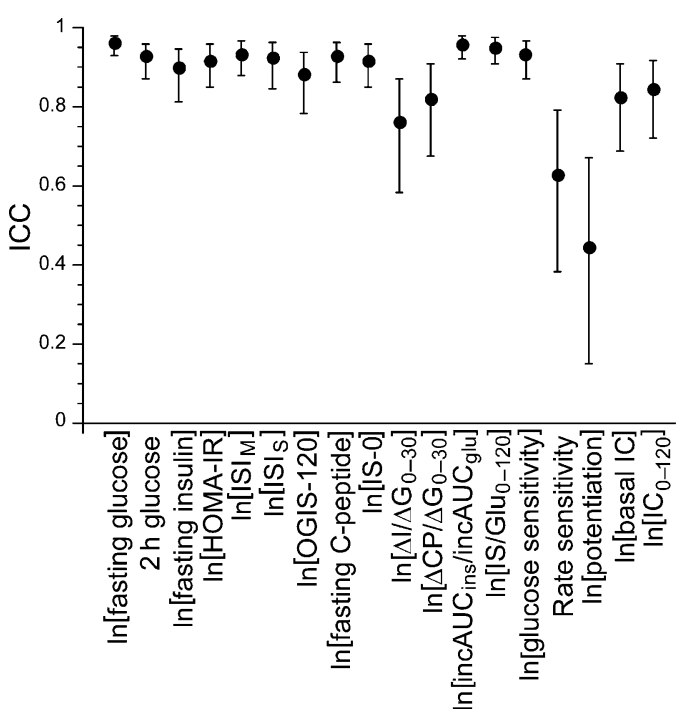

Fig. 4 ICC for each variable. These were computed using a one-way random effects model $( \pm 95 \% \mathrm{CI})$. An ICC $>0.75$ is considered excellent; $0.4-0.75$, fair to good; and $<0.4$, poor showed moderate variability. High variability for rate sensitivity has been reported in a previous study using this same model [1]. In spite of this considerable variability, rate sensitivity and potentiation may be useful to quantify treatment effects when the magnitude of change is large $[16,17]$.

To evaluate the degree to which within-subject variability contributes to the overall variability in our study population, we computed the ICC for each variable. In keeping with the higher CVs for certain measures, we observed poorer ICC values for the rate sensitivity and potentiation measures and lower ICC values for the early insulin and C-peptide responses compared with the integrated measures. The ICC is by definition population-based, and thus ICC results from this study would not be applicable to other studies. We therefore suggest that the $\mathrm{CV}$ values rather than the ICC results be used for study design or sample size computation.

While not the primary objective of the study, we also examined the variability of a number of surrogate measures of insulin sensitivity. Different measures of insulin sensitivity using fasting measures, formulas incorporating different time points during the OGTT and the OGIS-120 model all showed reasonable variability.

Measures of the insulin response cannot be interpreted alone, but must be assessed relative to the prevailing level of insulin sensitivity. The relationship between the acute insulin response and insulin sensitivity derived from an IVGTT has been shown to be hyperbolic in nature, and the 
Table 3 Sample size estimates for paired $t$ test

\begin{tabular}{|c|c|c|c|}
\hline Variable & $\begin{array}{l}\text { Sample size } \\
\text { for } 20 \% \\
\text { change }\end{array}$ & $\begin{array}{l}\text { Sample size } \\
\text { for } 30 \% \\
\text { change }\end{array}$ & $\begin{array}{l}\text { Sample size } \\
\text { for } 50 \% \\
\text { change }\end{array}$ \\
\hline Fasting glucose & 3 & 3 & 2 \\
\hline Fasting insulin & 20 & 11 & 6 \\
\hline HOMA-IR & 19 & 10 & 6 \\
\hline $\mathrm{ISI}_{\mathrm{M}}$ & 18 & 10 & 5 \\
\hline ISI $_{S}$ & 23 & 12 & 6 \\
\hline OGIS-120 & 6 & 4 & 3 \\
\hline Fasting C-peptide & 8 & 5 & 3 \\
\hline IS-0 & 8 & 5 & 3 \\
\hline$\Delta \mathrm{I}_{0-30} / \Delta \mathrm{G}_{0-30}$ & 181 & 89 & 39 \\
\hline$\Delta \mathrm{CP}_{0-30} / \Delta \mathrm{G}_{0-30}$ & 74 & 37 & 17 \\
\hline IncAUC $_{\text {ins }} /$ incAUC $_{\text {glu }}$ & 41 & 21 & 10 \\
\hline IncAUC $_{C P} /$ incAUC $_{\text {glu }}$ & 22 & 12 & 6 \\
\hline $\mathrm{IS} / \mathrm{Glu}_{0-120}$ & 21 & 12 & 6 \\
\hline Glucose sensitivity & 28 & 15 & 8 \\
\hline Potentiation & 68 & 34 & 16 \\
\hline Basal IC & 8 & 5 & 3 \\
\hline $\mathrm{IC}_{0-120}$ & 10 & 6 & 4 \\
\hline
\end{tabular}

For definitions, see Table 1

product of the two (frequently called the disposition index) has been used as a measure of beta cell function [18]. It has therefore been assumed that the relationship between any two measures of insulin sensitivity and insulin release is hyperbolic. However, to truly determine whether a hyperbolic relationship exists, the variability of both measures needs to be accounted for in the analyses, an important statistical step that is often overlooked in analysis of this hyperbolic relationship.

It is important to recognise that this study was not designed to determine the validity of measures of beta cell function and insulin sensitivity or to compare one measure with another. However, our study does provide the data from which sample size calculations can be made for longitudinal or interventional studies where within-subject variability is important. Table 3 illustrates clearly that the use of measures such as the early insulin response will require much larger sample sizes than the incremental AUC approach to detect a similar percentage change in response. Further, use of measures that are based on C-peptide require smaller sample sizes for estimating both insulin secretion and insulin sensitivity.

Our study was not designed to determine the mechanisms underlying the variability in OGTT measures of beta cell function. Possible mechanisms include variation in the secretion of, or response to, incretin hormones; changes in gastrointestinal motility and absorption; the impact of changes in recent glucose exposure, leading to a priming effect; and changes in physical activity levels. In premenopausal women, glucose metabolism differs in the different phases of the menstrual cycle [19] and this could therefore be a factor. While subjects were instructed to maintain their usual activity and diet, these variables are somewhat difficult to control in free-living adults. An intervention, such as provision of, or instruction in, a standardised diet for the 3 days preceding the OGTT test may have decreased variability, as would controlling for the phase of the menstrual cycle, but this is an impractical approach in large epidemiological or interventional studies. As the aim of the present study was to evaluate variability in OGTT-derived measures in free-living adults, no dietary or menstrual phase standardisation was included in the study design.

A limitation of this study was the exclusion of a few outlying data points. Outliers will in fact contribute to the overall variability of any study. On the other hand, inclusion of the outliers dramatically skewed the CV results. To prevent investigator bias we used a statistical approach using the ESD statistic to exclude outliers. In addition, negative values were dropped, since $\ln$ transformation cannot be performed. One out of $74(1.4 \%)$ of the OGTTs in our study had a negative $\Delta \mathrm{I}_{0-30} / \Delta \mathrm{G}_{0-30}$. In general, such negative insulin responses are uncommon. For example, we found 24/2027 (1.2\%) subjects had negative or zero $\Delta \mathrm{I}_{0-30} / \Delta \mathrm{G}_{0-30}$ responses in the American Diabetes Association Genetics of Non-insulin Dependent Diabetes (GENNID) study (unpublished data), a percentage very similar to our findings here. Of interest, use of the ISI $_{S}$ resulted in seven subjects being excluded for having negative values (four with IGT and three with diabetes). This is not surprising, since high $120 \mathrm{~min}$ insulin values can result in a large negative term in the equation and an overall negative ISI $_{S}$. This defect is not present in HOMA-IR or the $\mathrm{ISI}_{\mathrm{M}}$.

In conclusion, we have determined the within-subject variability for a number of measures that can be derived from results from an OGTT. We found that measures based on the early insulin response were highly variable, and that measures that utilise C-peptide or incorporate multiple time points demonstrate reduced variability, but clearly also increase the effort and cost of the test. Such factors must be considered when designing clinical studies, where withinsubject variability can dramatically affect sample size requirements, study procedures and overall study costs.

Acknowledgements We would like to thank the participants and the nurses on the Diabetes Group and Clinical Research Unit at the VA Puget Sound Health Care System for their assistance. We thank R. Vogel and M. Watts for performing the glucose and insulin assays. This work was supported by the Department of Veteran Affairs and National Institutes of Health (NIH) grant DK-17047. K. M. Utzschneider is the recipient of a VA Career Development Award, and S. E. Kahn is the recipient of an American Diabetes Association Distinguished Clinical Scientist Award.

Duality of interest The authors declare that there is no duality of interest associated with this manuscript. 


\section{References}

1. Mooy JM, Grootenhuis PA, de Vries H et al (1996) Intraindividual variation of glucose, specific insulin and proinsulin concentrations measured by two oral glucose tolerance tests in a general Caucasian population: the Hoorn Study. Diabetologia 39:298-305

2. Yudkin JS, Alberti KG, McLarty DG, Swai AB (1990) Impaired glucose tolerance. BMJ 301:397-402

3. Harding PE, Oakley NW, Wynn V (1973) Reproducibility of oral glucose tolerance data in normal and mildly diabetic subjects. Clin Endocrinol (Oxf) 2:387-395

4. Wolever TM, Chiasson JL, Csima A et al (1998) Variation of postprandial plasma glucose, palatability, and symptoms associated with a standardized mixed test meal vs $75 \mathrm{~g}$ oral glucose. Diabetes Care 21:336-340

5. Morgan C, Lazarow A (1963) Immunoassay of insulin: two antibody systems. Diabetes 12:115-126

6. Van Cauter E, Mestrez F, Sturis J, Polonsky KS (1992) Estimation of insulin secretion rates from C-peptide levels. Comparison of individual and standard kinetic parameters for C-peptide clearance. Diabetes 41:368-377

7. Mari A, Schmitz O, Gastaldelli A, Oestergaard T, Nyholm B, Ferrannini E (2002) Meal and oral glucose tests for assessment of $\beta$-cell function: modeling analysis in normal subjects. Am J Physiol Endocrinol Metab 283:E1159-E1166

8. Levy JC, Matthews DR, Hermans MP (1998) Correct homeostasis model assessment (HOMA) evaluation uses the computer program. Diabetes Care 21:2191-2192

9. Mari A, Pacini G, Murphy E, Ludvik B, Nolan JJ (2001) A model-based method for assessing insulin sensitivity from the oral glucose tolerance test. Diabetes Care 24:539-548
10. Matsuda M, DeFronzo RA (1999) Insulin sensitivity indices obtained from oral glucose tolerance testing: comparison with the euglycemic insulin clamp. Diabetes Care 22:1462-1470

11. Stumvoll M, Mitrakou A, Pimenta W et al (2000) Use of the oral glucose tolerance test to assess insulin release and insulin sensitivity. Diabetes Care 23:295-301

12. van Belle G, Martin DC (1993) Sample size as a function of coefficient of variation and ratio of means. Am Stat 47:165-167

13. Efron B, Tibshirani R (1993) An introduction to the bootstrap. Chapman \& Hall/CRC, Boca Raton

14. Abbate SL, Fujimoto WY, Brunzell JD, Kahn SE (1993) Effect of heparin on insulin-glucose interactions measured by the minimal model technique: Implications for reproducibility using this method. Metabolism 42:353-357

15. Schousboe K, Henriksen JE, Kyvik KO, Sorensen TI, Hyltoft Petersen P (2002) Reproducibility of S-insulin and B-glucose responses in two identical oral glucose tolerance tests. Scand J Clin Lab Invest 62:623-630

16. Mari A, Nielsen LL, Nanayakkara N, Defronzo RA, Ferrannini E, Halseth A (2006) Mathematical modeling shows exenatide improved beta-cell function in patients with type 2 diabetes treated with metformin or metformin and a sulfonylurea. Horm Metab Res 38:838-844

17. Mari A, Gastaldelli A, Foley JE, Pratley RE, Ferrannini E (2005) Beta-cell function in mild type 2 diabetic patients: Effects of 6month glucose lowering with nateglinide. Diabetes Care 28:11321138

18. Kahn SE, Prigeon RL, McCulloch DK et al (1993) Quantification of the relationship between insulin sensitivity and $\beta$-cell function in human subjects. Evidence for a hyperbolic function. Diabetes 42:1663-1672

19. Valdes CT, Elkind-Hirsch KE (1991) Intravenous glucose tolerance test-derived insulin sensitivity changes during the menstrual cycle. J Clin Endocrinol Metab 72:642-646 